\title{
Maternal smoking during pregnancy and childhood overweight and fat distribution: the KOALA Birth Cohort Study
}

Citation for published version (APA):

Timmermans, S. H., Mommers, M., Gubbels, J. S., Kremers, S. P. J., Stafleu, A., Stehouwer, C. D. A., Prins, M. H., Penders, J., \& Thijs, C. (2014). Maternal smoking during pregnancy and childhood overweight and fat distribution: the KOALA Birth Cohort Study. Pediatric Obesity, 9(1), e14-e25. https://doi.org/10.1111/j.2047-6310.2012.00141.x

Document status and date:

Published: 01/01/2014

DOI:

10.1111/j.2047-6310.2012.00141.x

Document Version:

Publisher's PDF, also known as Version of record

Document license:

Taverne

Please check the document version of this publication:

- A submitted manuscript is the version of the article upon submission and before peer-review. There can be important differences between the submitted version and the official published version of record.

People interested in the research are advised to contact the author for the final version of the publication, or visit the DOI to the publisher's website.

- The final author version and the galley proof are versions of the publication after peer review.

- The final published version features the final layout of the paper including the volume, issue and page numbers.

Link to publication

\footnotetext{
General rights rights.

- You may freely distribute the URL identifying the publication in the public portal. please follow below link for the End User Agreement:

www.umlib.nl/taverne-license

Take down policy

If you believe that this document breaches copyright please contact us at:

repository@maastrichtuniversity.nl

providing details and we will investigate your claim.
}

Copyright and moral rights for the publications made accessible in the public portal are retained by the authors and/or other copyright owners and it is a condition of accessing publications that users recognise and abide by the legal requirements associated with these

- Users may download and print one copy of any publication from the public portal for the purpose of private study or research.

- You may not further distribute the material or use it for any profit-making activity or commercial gain

If the publication is distributed under the terms of Article $25 \mathrm{fa}$ of the Dutch Copyright Act, indicated by the "Taverne" license above, 


\title{
Maternal smoking during pregnancy and childhood overweight and fat distribution: the KOALA Birth Cohort Study
}

\author{
S. H. Timmermans ${ }^{1}$, M. Mommers ${ }^{1}$, J. S. Gubbels ${ }^{2}$, S. P. J. Kremers ${ }^{2}$, A. Stafleu ${ }^{3}$, \\ C. D. A. Stehouwer ${ }^{4,5}$, M. H. Prins ${ }^{1}$, J. Penders ${ }^{1}$ and C. Thijs ${ }^{1}$ \\ ${ }^{1}$ Department of Epidemiology, CAPHRI School for Public Health and Primary Care, Maastricht University Medical Centre, \\ Maastricht, The Netherlands; ${ }^{2}$ Department of Health Promotion, NUTRIM School for Nutrition, Toxicology and Metabolism, \\ Maastricht University Medical Centre, Maastricht, The Netherlands; ${ }^{3}$ TNO, Zeist, The Netherlands; ${ }^{4}$ Department of Internal \\ Medicine, Maastricht University Medical Centre, Maastricht, The Netherlands; ${ }^{5}$ Cardiovascular Research Institute Maastricht \\ (CARIM), Maastricht University Medical Centre, Maastricht, The Netherlands
}

Received 31 March 2012; revised 9 December 2012; accepted 10 December 2012

\section{What is already known about this subject}

- There is an association between maternal smoking during pregnancy and higher body mass index (BMI) and overweight in childhood.

\section{What this study adds}

- The association between maternal smoking during pregnancy and childhood overweight develops with age, starting with a lower birth weight, followed by weight catch-up in the first year after birth, finally leading to overweight at school age.

- Children of mothers who had smoked during pregnancy had a higher risk of exceeding the 85th percentile of BMI, waist circumference and total skinfold thickness at school age.

\section{Summary}

Background: Maternal smoking during pregnancy is associated with childhood overweight, but the association with fat distribution is not clear.

Objective: To explore the longitudinal association between smoking during pregnancy and childhood overweight and fat distribution.

Methods: In the KOALA Birth Cohort Study, repeated questionnaires were administered to 2698 motherchild pairs, including questions on smoking at 14 and 34 weeks of pregnancy. Main outcomes were birth weight, weight gain in the first year, body mass index (BMI) $z$-scores and overweight (BMI $\geq 85$ th percentile) at 1, 2, 4-5 and 6-7 years $(n=1730)$ and waist circumference and four skinfold thicknesses measured at home visits at age 6-7 years in a subgroup $(n=418)$. We used multivariable linear and logistic regression, with generalized estimating equations (GEE) for repeated measurements.

Results: Maternal smoking was associated with lower birth weight, higher weight gain in the first year and increasing overweight after infancy (change with age $P=0.02$ in the GEE). Maternal smoking vs. nonsmoking during pregnancy was associated with a higher risk of the child exceeding the 85th percentile of BMI (adjusted odds ratio [aOR] 3.72; 95\% Cl 1.33-10.4), waist circumference (aOR 2.65; 95\% Cl 1.06-6.59) and sum of skinfold thicknesses (aOR 4.45; 95\% Cl 1.63-12.2) at the age of 6-7 years.

Conclusions: Maternal smoking during pregnancy is associated with lower birth weight, weight catch-up and development of overweight into childhood. 
Keywords: Childhood overweight, fat distribution, maternal smoking, prenatal programming.

Abbreviations: 95\% Cl, 95\% confidence interval; aB, regression coefficient, adjusted beta; aOR, adjusted odds ratio; BMI, body mass index; BS, biceps skinfold thickness; GEE, generalized estimating equations; SD, standard deviation; SFT, skinfold thickness; SIS, suprailiacal skinfold thickness; SS, subscapular skinfold thickness; TS, triceps skinfold thickness.

\section{Introduction}

The 'foetal origins of adult diseases' hypothesis states that maternal factors cause foetal malnutrition, which leads to changes in foetal growth and metabolism and results in changes in children's growth and metabolism (1). Catch-up growth in the first year after birth may lead to a higher body mass index (BMI) and higher fat mass in the children, which is important for the development of overweight in childhood (2-4). This concept is called prenatal programming. Various maternal factors can be important in prenatal programming: maternal smoking during pregnancy, for example, has been associated with low birth weight of the offspring (5). Many previous studies support the 'foetal origins of adult diseases' hypothesis for maternal smoking: these studies showed a positive association between maternal smoking during pregnancy and overweight in children aged between 5 and 16 years (6-15). Beyerlein et al. found that maternal smoking during pregnancy was mainly related to childhood overweight in the upper percentiles (16). The number of cigarettes smoked during pregnancy also appeared to be associated with childhood overweight $(9,14,17,18)$.

Most studies examining the association between maternal smoking, birth weight and subsequent weight status have used BMl or overweight as the outcome $(6,7,9,11-15)$. Although BMl is often considered a useful parameter to determine overweight in clinical practice, it does not distinguish between fat mass and lean mass (19). It is therefore possible that overweight in some children is incorrectly based on higher lean mass rather than on higher fat mass (20). Few studies have examined the association between maternal smoking and fat distribution, and their results have been inconsistent $(10,20-23)$.

The aim of the present study was to examine the association between maternal smoking during pregnancy and the development of childhood overweight and fat distribution in school-aged children. To this end, we studied the association between maternal smoking during pregnancy and birth weight, weight gain in the first year after birth, BMl $z$-scores and overweight at ages 1, 2, 4-5 and 6-7 years, as well as the upper percentiles ( $\geq 85 \%$ ) of waist circumfer- ence and different skinfold thicknesses (SFT) at age 6-7 years. We also examined the timing of smoking during pregnancy (at 14 and/or 34 weeks) and doseresponse relationships with the number of cigarettes smoked, as timing and dose may influence foetal development differently.

\section{Patients and methods}

\section{Study population and study design}

The present study was conducted within the context of the KOALA Birth Cohort Study, a prospective cohort study in the Netherlands whose general study design was described in detail previously (24). Healthy pregnant women from the general population were recruited from midwife practices for a study on pregnancy-related pelvic girdle pain. These women $(n=2343)$ were the 'conventional recruitment' group. Pregnant women for an additional 'alternative recruitment' group $(n=491)$ were recruited through organic food shops, anthroposophic doctors and midwives, Steiner schools and dedicated magazines. Enrolment started in October 2000; all participants $(n=2834)$ were enrolled at around 14 weeks of pregnancy and gave written informed consent. Ethical approval was obtained from the Maastricht University/University Hospital Maastricht medical ethics committee.

Exclusion criteria for the present study were congenital disorders related to childhood growth (i.e. Down syndrome, Turner syndrome, Fallot's tetralogy, multiple disabilities, cystic fibrosis), perinatal infant death, prematurity (<37 weeks gestation), multiple pregnancy and parents withdrawing from the study before the birth or within 3 months after the birth. In total, 136 children were excluded and 2698 children were available for the final analyses (Fig. 1).

The mothers filled out questionnaires at 14 and 34 weeks of pregnancy, yielding data on maternal tobacco smoke exposure and alcohol use, and background characteristics such as height and weight before pregnancy and the mother's age and educational level. Two weeks after the birth, we collected obstetric reports and questionnaires completed by the mothers to retrieve data on gestational 


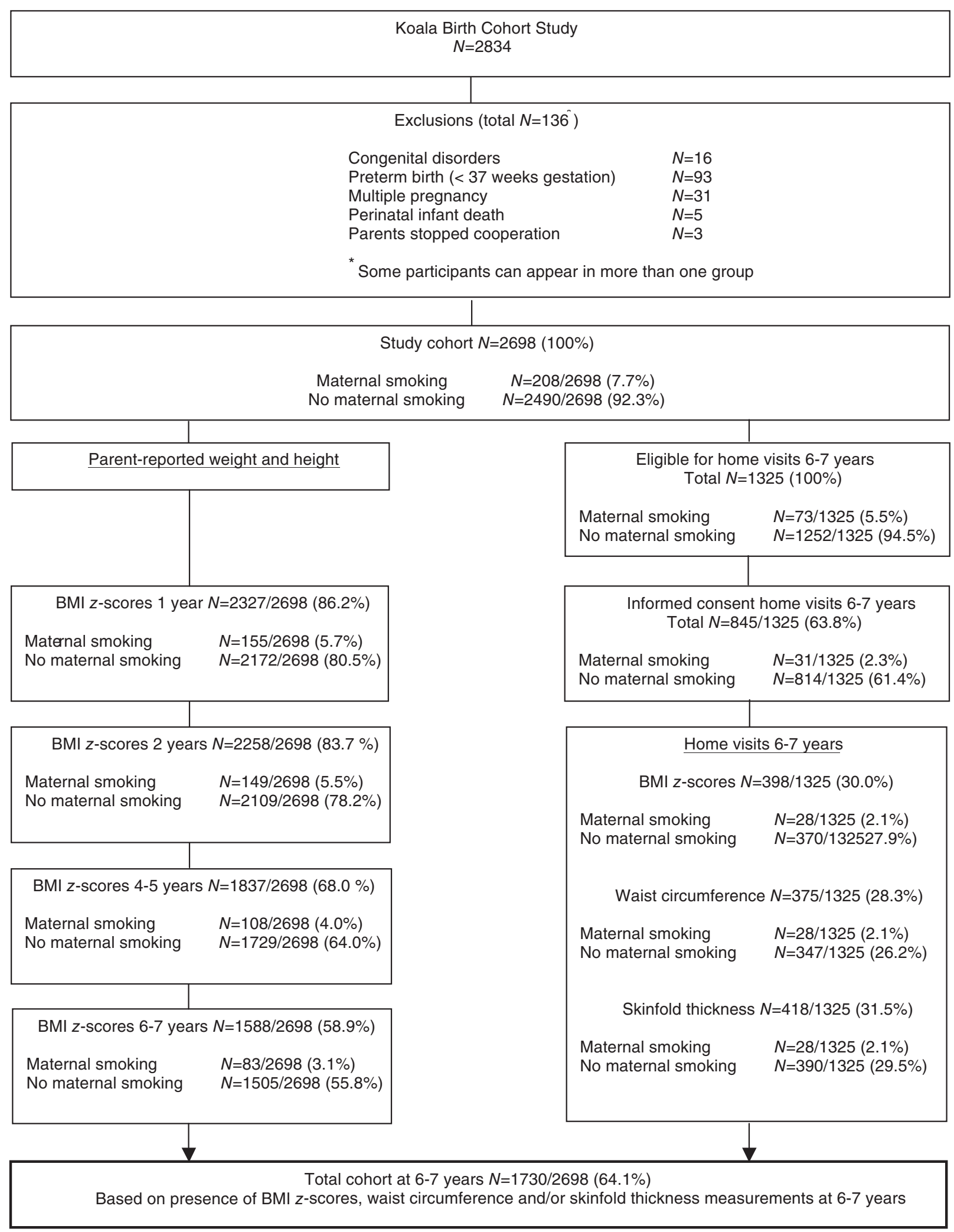

Figure 1 Flow chart of participants in the present study. 
age and birth weight. Height and weight of the children were recorded by means of questionnaires at the ages of $1,2,4-5$ and $6-7$ years. When the children were 6-7 years old, a subgroup of them were visited at home visits by trained research assistants to measure their height, weight, waist circumference and SFT. Children were eligible for home visits if their mothers had donated a blood sample at 34 weeks of pregnancy $(n=1325)$. In total, $63.8 \%$ of the families $(n=845)$ gave additional informed consent for the home visits.

\section{Assessment of exposure}

At 14 weeks of pregnancy, women were asked: 'Do you smoke?', with response options 'No, never'; 'No, but I used to smoke ... cigarettes a day'; or 'Yes, I smoke about . . . cigarettes a day'. At 34 weeks of pregnancy, women were asked: 'How many cigarettes do you smoke a day?', and they were also asked about passive smoking ('Hardly, less than 1 hour a week'; 'Sometimes, but less than 1 hour a day'; 'Yes, between 1 and 4 hours a day'; or 'Yes, more than 4 hours a day'). We used the information from both questionnaires to categorize women into the following groups: no maternal smoking and no passive smoking during pregnancy (reference group); no maternal smoking and less than $1 \mathrm{~h}$ a day of passive smoking; no maternal smoking and more than $1 \mathrm{~h}$ a day of passive smoking; and maternal smoking reported during pregnancy. This classification provided us with a control group of pregnant women who were neither active nor passive smokers. For a more refined analysis, we divided maternal smoking into smoking only at 14 weeks of pregnancy, smoking only at 34 weeks of pregnancy and smoking at both 14 and 34 weeks of pregnancy. Our analysis of the doseresponse relationship used the reported numbers of cigarettes a day at 14 weeks and at 34 weeks of pregnancy as two separate continuous variables.

\section{Assessment of outcomes}

Midwives were asked to report the birth weight of the child in grams, and this was checked against the maternal self-report from the questionnaire administered 2 weeks after birth to resolve missing values and electronic scanning and writing errors; if discrepancies were not resolved, birth weight was considered missing in the analysis. Weight gain in the first year after birth was calculated by subtracting birth weight from reported weight at 1 year.

Information on the child's height, weight and age at the time of measurement was reported by parents and collected by means of questionnaires. At age 1 and 2 years, parents were asked to report the most recent weight and height measured at the child health clinic, and to also report the age (in months) at the time of these measurements. From age 4 years on, parents were asked to measure weight (in kilograms with one decimal) and height (in centimetres), with the child wearing light clothes and no shoes, and to report the exact date of measurement.

In a subgroup of children $(n=418)$, height, weight, waist circumference and SFT were measured during home visits by trained research assistants at the age of 6-7 years, with the children wearing only their underpants. Height was measured with a portable stadiometer (Leicester height measure) and weight was measured with a digital scale (HE-5, CAS Corp., East Rutherford, NJ, USA) and recorded in millimetres and grams (rounded off to $100 \mathrm{~g}$ ), respectively. Waist circumference was measured with a tape measure at the end of a normal expiration in standing position, halfway between the lower rib and the iliac crest, and recorded in centimetres. This measurement was done in duplicate and the results were averaged. SFT was measured using the Harpenden Skinfold Caliper (Baty International, Sussex, UK). Biceps skinfold (BS), triceps skinfold (TS), subscapular skinfold (SS) and suprailiacal skinfold (SIS) were measured in millimetres. These were used to calculate the total sum of SFTs (BS + TS + SS + SIS), peripheral SFT (BS + TS), central SFT (SS + SIS) and the ratio of central-to-peripheral SFT ((BS + TS): (SS + SIS)), as a proxy for central fat distribution (20). The child's exact age (in days) was computed from the date of the home visit and the date of birth, so that the age of the measurement could be taken into account in the analyses.

\section{Statistical analyses}

BMI was calculated as weight divided by height squared $\left(\mathrm{kg} \mathrm{m}^{-2}\right)$, and $z$-scores were calculated to adjust for sex and age, the reference group being children from the Dutch National Growth Study (25). BMl $z$-scores were used both as a continuous outcome and as a dichotomous outcome: no overweight vs. overweight (BMl z-scores $\geq 85$ th percentile, corresponding to a $z$-score 21.04$)$. We compared the results on overweight from the parentreported data and the data from the home visits to assess misclassifications and possible systematic underreporting.

We used multivariable linear regression to analyze the association between maternal smoking and birth weight, weight gain in the first year after birth, waist 
circumference and SFT indices. We used multivariable logistic regression to analyze the association between maternal smoking and overweight at 6-7 years, waist circumference and SFT in children exceeding the 85th percentile. Generalized estimating equations (GEE) analyses with an unstructured correlation structure were used to analyze the longitudinal association between maternal smoking and childhood BMl z-scores (linear GEE) and overweight (logistic GEE), using all available parent-reported repeated measurements until age 6-7 years.

To evaluate whether results differed between the conventional and alternative recruitment groups, we tested for statistical interaction between maternal smoking during pregnancy and recruitment group. None of these interactions were statistically significant, indicating no need to perform stratified analyses. In the GEE analysis, we evaluated the interaction between maternal smoking and age as a continuous variable (child's age at time of BMI measurements).

Potential confounders that were taken into account were gender of the child; recruitment group (conventional, alternative); maternal age at time of pregnancy ( $\leq 24$ years, 25-39 years, $\geq 40$ years); maternal BMl before pregnancy $\left(<18.5,18.5-25, \geq 25 \mathrm{~kg} \mathrm{~m}^{-2}\right)$; maternal educational level (low, intermediate, high) and maternal alcohol use during pregnancy (no alcohol use during pregnancy, alcohol use at 14 and/or 34 weeks of pregnancy). Crude analyses were adjusted only for recruitment roup; adjusted analyses were adjusted for all potential confounders. Weight gain in the first year after birth, waist circumference and SFT indices were additionally adjusted for age at time of measurement.

We used SPSS 15.0 for Windows (Chicago, IL, USA) for all our analyses. $P$-values $<0.05$ were considered statistically significant.

\section{Results}

Maternal and child characteristics at baseline are presented in Table 1. Children lost to follow-up were more likely to have mothers with lower educational level and/or mothers who had smoked during pregnancy (Supporting Information Appendix S1). More than half of the children of mothers who had smoked during pregnancy were lost to follow-up at 6-7 years (compared to the $35.5 \%$ loss to follow-up for the total cohort). There were no substantial differences in characteristics between the total cohort at baseline $(n=2698)$ and after 6-7 years of follow-up $(n=1730)$. In total, 208 of the 2698 (7.7\%) women reported smoking during pregnancy. At the end of the follow-up, 91 of the 1730 (5.3\%) women whose children still participated in the study had smoked during pregnancy.

\section{Early outcomes}

Children of mothers who had smoked during pregnancy had lower birth weight compared to the reference group (regression coefficient adjusted Beta (aB) $-186 \mathrm{~g} ; 95 \% \mathrm{Cl}-257$ to -166$)$ (Table 2). Refined analysis showed that only maternal smoking at both 14 and 34 weeks of pregnancy was associated with lower birth weight $(\mathrm{aB}-233 \mathrm{~g} ; 95 \% \mathrm{Cl}-299$ to $-147)$. We found a significant dose-response relationship between the reported number of cigarettes smoked at 34 weeks of pregnancy and birth weight (aB -18 g per cigarette per day; 95\% $\mathrm{Cl}-29$ to -7 ), and a borderline significant dose-response relationship with smoking reported at 14 weeks of pregnancy $(\mathrm{aB}-13 \mathrm{~g}$ per cigarette per day; $95 \% \mathrm{Cl}-26$ to 1$)$.

Children of mothers who had smoked during pregnancy gained significantly more weight in the first year after birth than the reference group (aB $229 \mathrm{~g}$; 95\% Cl 72 to 385; Table 2), and this mean weight gain was even larger than the mean birth weight deficit of $186 \mathrm{~g}$. Compared to non-smoking during pregnancy, smoking at 34 weeks of pregnancy $(\mathrm{aB}$ $456 \mathrm{~g} ; 95 \% \mathrm{Cl} 18$ to 895) and smoking at both 14 and 34 weeks of pregnancy (aB $191 \mathrm{~g} ; 95 \% \mathrm{Cl} 18$ to 364) were significantly related to more weight gain in the first year after birth. We found no dose-response relationships between the numbers of cigarettes smoked at 14 and 34 weeks of pregnancy and weight gain in the first year after birth.

\section{BMI z-scores and overweight}

Children of mothers who had smoked during pregnancy showed no substantial differences in mean BMl z-scores at any age compared to children in the reference group (Table 2). We found a significant interaction between maternal smoking and the child's age (test for age interaction $P=0.02$ ), indicating that the association between maternal smoking and overweight increased with age, reaching its highest value at 6-7 years (adjusted odds ratio [aOR] 1.95; 95\% Cl 1.05 to 3.62; Fig. 2).

The association between maternal smoking and overweight at age 6-7 years based on data measured at the home visits was even stronger (aOR 3.68; $95 \% \mathrm{Cl} 1.54$ to 8.81 ; Table 3). When comparing the data from the parent-reported measurements and those from the home visits we found that the parentreported data underreported overweight, even more 


\begin{tabular}{|c|c|c|c|}
\hline & \multirow{2}{*}{$\begin{array}{l}\frac{\text { Total cohort }^{*}}{(n=2698)} \\
n(\%)\end{array}$} & \multicolumn{2}{|c|}{ Maternal smoking* } \\
\hline & & $\begin{array}{l}\text { 'Yes' }(n=208) \\
n(\%)\end{array}$ & $\begin{array}{l}{ }^{\prime} \mathrm{No}^{\prime \dagger}(n=2490) \\
n(\%)\end{array}$ \\
\hline \multicolumn{4}{|l|}{ Child characteristics } \\
\hline \multicolumn{4}{|l|}{ Gender } \\
\hline Male & $1367(50.7)$ & $117(56.3)$ & $1250(50.2)$ \\
\hline Female & $1330(49.3)$ & $91(43.8)$ & $1239(49.8)$ \\
\hline \multicolumn{4}{|l|}{ Birth weight } \\
\hline$<2500 \mathrm{~g}$ & $36(1.3)$ & $1(0.5)$ & $35(1.4)$ \\
\hline $2500-4500 \mathrm{~g}$ & 2577 (95.5) & $203(97.6)$ & $2374(95.8)$ \\
\hline$>4500 \mathrm{~g}$ & $70(2.6)$ & $1(0.5)$ & $69(2.8)$ \\
\hline \multicolumn{4}{|c|}{ Maternal characteristics } \\
\hline \multicolumn{4}{|c|}{ Passive smoking at 34 weeks pregnancy } \\
\hline$<1 \mathrm{~h}$ week $^{-1}$ & $1754(65.0)$ & $30(14.1)$ & $1724(69.5)$ \\
\hline$<1 \mathrm{~h} \mathrm{~d}^{-1}$ & $623(23.1)$ & $62(29.8)$ & $561(22.6)$ \\
\hline$>1 \mathrm{hd}^{-1}$ & $308(11.4)$ & $114(54.8)$ & $194(7.8)$ \\
\hline \multicolumn{4}{|l|}{ Lifestyle } \\
\hline Conventional & $2233(82.8)$ & $203(97.6)$ & $2030(81.5)$ \\
\hline Alternative & $465(17.2)$ & $5(2.4)$ & $460(18.5)$ \\
\hline \multicolumn{4}{|l|}{ BMI before pregnancy } \\
\hline $\mathrm{BMl}<18.5$ & $76(2.8)$ & $15(7.2)$ & $61(2.5)$ \\
\hline BMl 18.5-25.0 & $1895(70.2)$ & $127(61.1)$ & $1768(71.5)$ \\
\hline $\mathrm{BMl} \geq 25.0$ & 706 (26.2) & 63 (30.3) & $643(26.0)$ \\
\hline \multicolumn{4}{|l|}{ Age at time of pregnancy } \\
\hline$<25$ years & $65(2.4)$ & $13(6.3)$ & $52(2.1)$ \\
\hline 25-39 years & $2542(94.2)$ & $188(90.4)$ & $2354(94.6)$ \\
\hline$\geq 40$ years & $88(3.3)$ & $6(2.9)$ & $82(3.3)$ \\
\hline \multicolumn{4}{|l|}{ Educational level } \\
\hline Low & $270(10.0)$ & 69 (33.2) & 201 (8.5) \\
\hline Intermediate & $1014(37.6)$ & $92(44.2)$ & $922(39.1)$ \\
\hline High & $1276(47.3)$ & $38(18.3)$ & $1238(52.4)$ \\
\hline \multicolumn{4}{|c|}{ Maternal alcohol use during pregnancy } \\
\hline No maternal alcohol use & $2196(81.4)$ & $162(78.3)$ & $2032(81.8)$ \\
\hline Exclusively at 14 weeks & $53(2.0)$ & $6(2.9)$ & $47(1.9)$ \\
\hline Exclusively at 34 weeks & $213(7.9)$ & $15(7.2)$ & $198(8.0)$ \\
\hline Both at 14 and 34 weeks & $233(8.6)$ & $24(11.6)$ & $209(8.4)$ \\
\hline
\end{tabular}

${ }^{*}$ Characteristics at baseline. Numbers may not add up to total because of missing values.

†No maternal smoking during pregnancy also includes passive smokers.

BMl, body mass index.

so in the maternal smoking group than in the non-smoking group (see Supporting Information Appendix S2).

\section{Fat distribution}

Compared to maternal non-smoking, maternal smoking during pregnancy was not associated with higher mean waist circumference at 6-7 years (Table 2), but the risk of a child exceeding the 85th percentile of waist circumference was more than doubled in children of mothers who had smoked
Table 1 Baseline characteristics of participants in the present study 


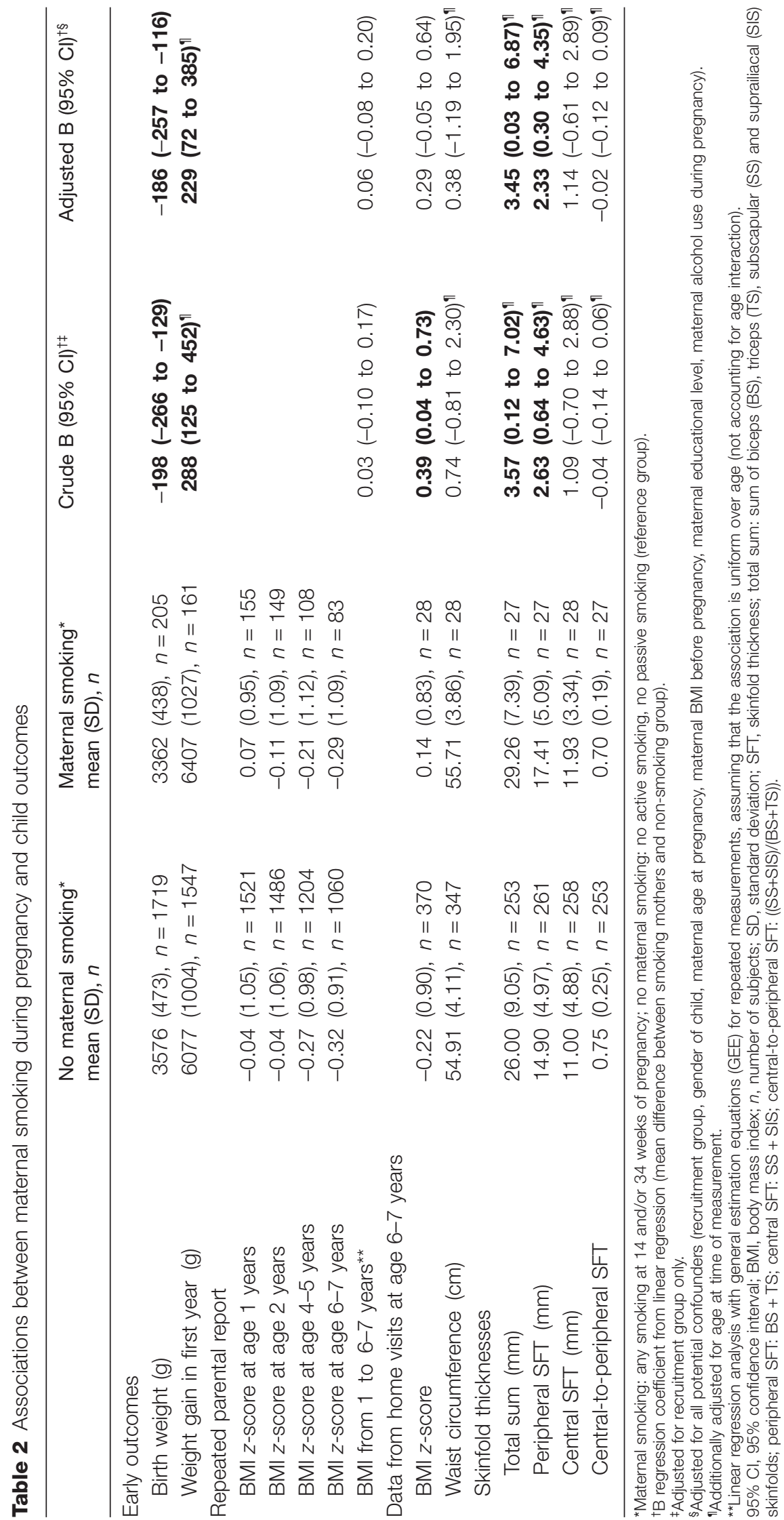




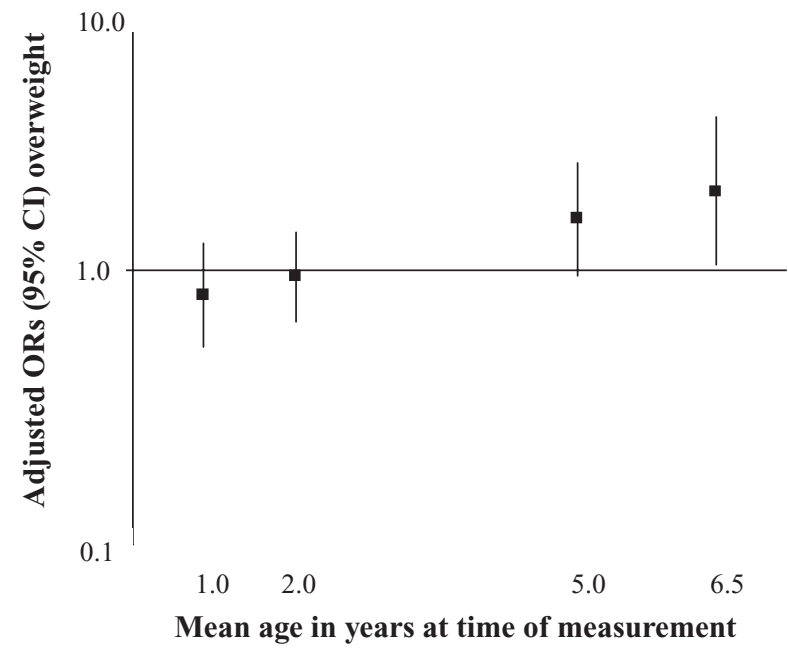

Figure 2 Association between maternal smoking during pregnancy and overweight until 6-7 years. Odds ratios (ORs) and 95\% confidence intervals (95\% Cl, vertical bars) for overweight (BMI z-scores $\geq 85$ th percentile; $z$-score $\geq 1.04$ ) in children of women who smoked actively during pregnancy (any maternal smoking at 14 and/or 34 weeks of pregnancy) vs. the non-exposed reference group (no active nor passive smoking at 14 and 34 weeks of pregnancy). Analysis based on longitudinal logistic regression analysis with generalized estimating equations (GEE) and adjusted for all potential confounders: gender of child, recruitment group, maternal age at time of pregnancy, maternal BMI before pregnancy, maternal educational level and maternal alcohol use during pregnancy, as well as an age-smoking interaction term to allow for changes in the odds ratio with increasing age of the child (interaction $P$-value 0.02).

during pregnancy vs. those whose mothers had not. The risk of an exposed child exceeding the 85th percentile of total SFT was more than quadrupled (aOR 4.45; 95\% Cl 1.63-12.2) compared to children of non-smoking mothers. The association between maternal smoking during pregnancy and peripheral SFT reached statistical significance, but the associations between maternal smoking and central SFT and central-to-peripheral SFT did not (Tables 2 and 3 ).

Dose-response relationships with the numbers of cigarettes smoked were only statistically significant for the relationships between maternal smoking at 14 weeks of pregnancy and the total sum of SFTs (aB $0.47 \mathrm{~mm}$ per cigarette per day; $95 \% \mathrm{Cl} 0.01$ to 0.92 ) as well as peripheral SFT (aB $0.30 \mathrm{~mm}$ per cigarette per day; $95 \% \mathrm{Cl} 0.03$ to 0.57 ). We found no association between the timing of smoking ( 14 and/or 34 weeks of pregnancy) and the SFT indices.

\section{Discussion}

The present prospective cohort study showed that maternal smoking during pregnancy is associated with lower birth weight and higher weight gain in the first year after birth, even exceeding the initial birth weight deficit. We also found that the strength of the association between maternal smoking and overweight increased with age after infancy (up to 6-7 years), suggesting a development of overweight into school age. The increased risk that the waist circumference and the sum of SFTs exceeded the 85th percentile at 6-7 years among the children of mothers who smoked may indicate that this was due to fat mass rather than lean mass.

The relation between maternal smoking during pregnancy and low birth weight has been studied extensively $(2,26)$. Valero de Bernabé et al. (26) described maternal smoking during pregnancy as one of the most important risk factors for low birth weight. Their findings are comparable to ours, as they reported birth weights that were 150-200 g lower among children of mothers who smoked during pregnancy. Fenercioglu et al. (27) studied maternal smoking in relation to growth velocities of weight, height and head circumference. They found that at 6 months, children of mothers who had smoked during pregnancy did not show sufficient weight gain to compensate for their weight deficit at birth. We found that such children had greater weight gain in the first year after birth and even had a slightly higher BMI $z$-score at age 1 year compared to the reference group. This suggests that the catch-up growth that compensates for the weight deficit occurs in the second half of the first year after birth.

Meta-analyses by Oken et al. (6) and Huang et al. (7) both described an increased risk of developing overweight in children of mothers who smoked during pregnancy, with a pooled odds ratio around 1.5. These findings correspond with our results from the GEE analysis, which showed that the strength of the association increases as the child grows older; however, the odds ratio we found at age 6-7 years (1.95 for overweight based on parent-reported data and 3.68 based on data measured at home visits) was higher than that found in the meta-analyses. This may be due to dilution by misspecification of the age effect in previous studies, or other sources of measurement error.

So far, few studies on the association between maternal smoking during pregnancy and fat distribution have been performed, and the ones that have used different measures of fat distribution. The 
Table 3 Associations between maternal smoking during pregnancy and child outcomes (children exceeding the 85th percentile of BMI, waist circumference and skinfold thickness)

\begin{tabular}{|c|c|c|c|c|}
\hline & $\begin{array}{l}\text { No maternal } \\
\text { smoking* } \\
n / N(\%)\end{array}$ & $\begin{array}{l}\text { Maternal } \\
\text { smoking } \\
n / N(\%)\end{array}$ & $\begin{array}{l}\text { Crude OR } \\
(95 \% \mathrm{Cl})^{\dagger \ddagger}\end{array}$ & $\begin{array}{l}\text { Adjusted OR } \\
(95 \% \mathrm{Cl})^{\dagger \S}\end{array}$ \\
\hline \multicolumn{5}{|l|}{$\begin{array}{l}\text { Repeated parental reports } \\
\text { on overweight }{ }^{\dagger \dagger}\end{array}$} \\
\hline Overweight at age 1 year & 228/1521 (15.0\%) & 23/155 (14.8\%) & & \\
\hline Overweight at age 2 years & $215 / 1486(14.5 \%)$ & $17 / 149(11.4 \%)$ & & \\
\hline Overweight at age $4-5$ years & 97/1204 (8.1\%) & $13 / 108(12.0 \%)$ & & \\
\hline Overweight at age 6-7 years & $62 / 1060(5.8 \%)$ & 10/83 (12.0\%) & & \\
\hline $\begin{array}{l}\text { Association of overweight } 1 \text { to } \\
6-7 \text { years }\end{array}$ & & & $1.05(0.74-1.50)$ & $1.03(0.71-1.49)$ \\
\hline \multicolumn{5}{|l|}{$\begin{array}{l}\text { Data from home visits at age 6-7 } \\
\text { years }\end{array}$} \\
\hline Overweight, BMl z-score $>P .85^{\dagger \dagger}$ & $31 / 370(8.4 \%)$ & $7 / 28(25.0 \%)$ & $3.92(1.52-10.1)$ & $3.72(1.33-10.4)$ \\
\hline $\begin{array}{l}\text { Waist circumference }>P .85 \\
(>58 \mathrm{~cm})^{\ddagger \ddagger}\end{array}$ & $45 / 347(13.0 \%)$ & $9 / 28(32.1 \%)$ & $3.12(1.32-7.39)^{\pi}$ & $2.65(1.06-6.59)^{4}$ \\
\hline \multicolumn{5}{|l|}{ Skinfold thicknesses } \\
\hline Total sum >P.85 (>32 mm) $)^{\ddagger \ddagger}$ & $32 / 253(12.6 \%)$ & 9/27 (33.3\%) & $3.68(1.50-9.02)^{n}$ & $4.45(1.63-12.2)^{n}$ \\
\hline Peripheral SFT >P.85 $(>19 \mathrm{~mm})^{\ddagger \neq}$ & $33 / 261(12.6 \%)$ & $8 / 27$ (29.6\%) & $3.26(1.30-8.18)^{\pi}$ & $2.86(1.05-7.81)^{4}$ \\
\hline Central SFT >P.85 (>14 mm) $)^{\ddagger \ddagger}$ & $36 / 258(14.4 \%)$ & $7 / 28(25 \%)$ & $2.18(0.85-5.55)^{\Uparrow}$ & $2.47(0.88-6.95)^{\Uparrow}$ \\
\hline $\begin{array}{l}\text { Central-to-peripheral >P.85 SFT } \\
(>0.94)^{\ddagger \ddagger}\end{array}$ & $36 / 253(14.2 \%)$ & $2 / 27$ (7.4\%) & $0.49(0.11-2.15)^{\uparrow}$ & $0.60(0.13-2.80)^{n}$ \\
\hline
\end{tabular}

*Maternal smoking: any smoking at 14 and/or 34 weeks of pregnancy; no maternal smoking: no active smoking, no passive smoking (reference group). tOR, odds ratio from logistic regression analysis.

${ }^{\ddagger}$ Adjusted for recruitment group only.

${ }^{\S}$ Adjusted for all potential confounders (recruitment group, gender of child, maternal age at pregnancy, maternal BMl before pregnancy, maternal educational level, maternal alcohol use during pregnancy).

"Additionally adjusted for age at time of measurement.

${ }^{*}$ Logistic regression analysis with General Estimation Equations (GEE) for repeated measurements, assuming that the association is uniform over age (no age interaction).

${ }^{+\dagger}$ Overweight: BMI >85th percentile (z-score $>1.04$, the reference group being children from the Dutch National Growth Study).

¥¥Using the distribution of the KOALA cohort (figures in brackets indicate $>85$ th percentile cut-off value, $P>0.85$ ).

$95 \% \mathrm{Cl}, 95 \%$ confidence interval; BMI, body mass index; $n$, number of participants exceeding 85 th percentile; $N$, total number of subjects; SFT, skinfold thickness; total sum: sum of biceps (BS), triceps (TS), subscapular (SS) and suprailiacal (SIS) skinfolds; peripheral SFT: BS + TS; central SFT: SS + SIS; central-to-peripheral SFT: ((SS + SIS)/(BS + TS)).

meta-analysis by Rogers et al. (20) yielded little evidence for an association between low birth weight and central fat distribution. Low birth weight was associated with higher waist circumference, but not with waist-to-hip ratio or central-to-peripheral SFT ratio. Our results fit this pattern, in that maternal smoking was related to lower birth weight and that children had a higher risk of exceeding the 85th percentile of waist circumference, but not that of central-to-peripheral SFT ratio. Syme et al. (28) studied magnetic resonance imaging-based measures of adiposity, and reported that maternal smoking during pregnancy was not associated with fat distribution in early puberty, whereas in late puberty, maternal smoking was associated with both higher subcutaneous and intra-abdominal fat mass.

\section{Strengths and limitations of the present study}

A strong point of the present study was that it was prospectively conducted in a large cohort. We used several questionnaires during pregnancy, which yielded extensive information on passive and active smoking during pregnancy. Another strong point was that we had data from repeated measurements of children's height and weight (parent-reported) and various anthropometric measurements relating to overweight and fat distribution (measured by research assistants). Since detailed and prospective information on background factors was available, we were able to adjust for many relevant confounders.

A limitation of the present study was that we used self-reported data on maternal smoking habits 
during pregnancy. Since most women nowadays are aware of the adverse effects of smoking during pregnancy on the foetus, the self-reported maternal smoking rates could have been an underestimation (29). However, Patrick et al. concluded that there was less underestimation of self-reported maternal smoking in studies that did not focus on smoking cessation than those studies who did (30). We therefore assume that we may have underestimated maternal smoking during pregnancy in the present study, but the effect is likely to have been small.

Another limitation was that repeated weight and height were parent-reported. One study showed both underestimation of children's weight and overestimation of their height by their parents, leading to lower BMl and lower prevalence of overweight (31), while another study found an overestimation of weight and therefore also of overweight in parentreported data (32). In our study, we found underestimation of overweight in parent-reported data compared to data from the home visits, especially in the smoking group (see Supporting Information Appendix S2). This explains why the OR for the BMI based on parent-reported height and weight at age 6-7 years (aOR 1.95) was smaller than that for the BMl based on home visits (aOR 3.68).

Another limitation is related to loss to follow-up. The follow-up rate among smoking mothers was somewhat lower than that among non-smokers (Supporting Information Appendix S1). However, selective loss to follow-up by itself is not enough to bias the results, as the follow-up rates should also differ with the outcome (overweight) and should do so differently for the two exposure groups (maternal smoking vs. non-smoking). Such bias caused by differential loss to follow-up is difficult to rule out entirely, but we would expect that such bias would tend to go in the opposite direction, as it seems more plausible that it would be the overweight children in the maternal smoking group who would show the highest rate of loss to follow-up, rather than the children with normal weight. This would then lead to an underestimated positive or even a negative association (biased $\mathrm{OR}<1.0$ if the true $\mathrm{OR}$ is 1.0), whereas we found the opposite $(O R>1.0)$. Moreover, the differential loss to follow-up would need to be implausibly large to explain the strength of the associations found in our study.

We did not discuss the potential effects of the timing of smoking (smoking only at 14 weeks or only at 34 weeks of pregnancy vs. continuous or no smoking) since we regard these subgroups as too small to fully analyze and interpret these results.
Finally, SFT might not be the most reliable measure of fat distribution, in view of its limited accuracy (33). However, the SFT measurements were performed by trained research assistants, and we had a reasonably large number of participants, so that any individual measurement errors did not greatly influence the results. Liem et al. studied various methods to estimate subcutaneous abdominal and intra-abdominal adipose tissue, and concluded that SFT measurements are a good, non-invasive and inexpensive method to predict subcutaneous fat in 6-7-year-old children (34).

In conclusion, the present prospective birth cohort study showed that maternal smoking during pregnancy is associated with the development of overweight in childhood (up to age 6-7 years). Our study adds to previous studies through its prospective, longitudinal design, with smoking status assessed repeatedly during pregnancy, as well as repeated measurements of BMI between birth and age 6-7 years. The finding that maternal smoking during pregnancy was associated with childhood overweight, and especially that the overweight increased with age, suggests a lasting effect that may increase even further in puberty, adolescence and adulthood, with major public health implications.

\section{Conflict of interest statement}

Financial support for the KOALA Birth Cohort Study until 6-7 years of follow-up was provided by the Triodos Foundation, Phoenix Foundation, Raphaël Foundation, Iona Foundation, and Foundation for the Advancement of Heilpedagogie, the Friesland Campina dairy company (Leeuwarden, NL) and the Dutch Sugar Bureau (all in the Netherlands), as well as by the Dutch Ministry of Economic Affairs, the Netherlands Organisation for Health Research and Development (ZonMw project no. 2100.0090) and the Netherlands Asthma Foundation (grants nos. 3.2.03.48 and 3.2.07.022). The sponsors had no influence on the data analysis or the publication of the results. The authors declare that they have no conflict of interest.

\section{Acknowledgements}

We declare that all authors (SHT, MM, JSG, SPJK, AS, CDAS, MHP, JP and CT) contributed substantially to the conception and design of the study, data collection and analysis, interpretation and writing of this article. Also, all authors contributed substantially to drafting and revising the article and all have seen and approved the final submitted version. We would 
like to thank the parents and children for participating in the KOALA Birth Cohort Study.

\section{References}

1. Hales CN, Barker DJ. The thrifty phenotype hypothesis. Br Med Bull 2001; 60: 5-20.

2. Ong KK, Ahmed ML, Emmett PM, Preece MA, Dunger DB. Association between postnatal catch-up growth and obesity in childhood: prospective cohort study. BMJ 2000; 320: 967-971.

3. Law CM, Barker DJ, Osmond C, Fall CH, Simmonds SJ. Early growth and abdominal fatness in adult life. J Epidemiol Community Health 1992; 46: 184-186.

4. Ong KK, Preece MA, Emmett PM, Ahmed ML, Dunger DB. Size at birth and early childhood growth in relation to maternal smoking, parity and infant breast-feeding: longitudinal birth cohort study and analysis. Pediatr Res 2002; 52: 863-867.

5. Kramer MS. Determinants of low birth weight: methodological assessment and meta-analysis. Bull World Health Organ 1987; 65: 663-737.

6. Oken E, Levitan EB, Gillman MW. Maternal smoking during pregnancy and child overweight: systematic review and meta-analysis. Int J Obes (Lond) 2008; 32: 201210.

7. Huang JS, Lee TA, Lu MC. Prenatal programming of childhood overweight and obesity. Matern Child Health $J$ 2007; 11: 461-473.

8. Raum E, Kupper-Nybelen J, Lamerz A, Hebebrand J, Herpertz-Dahlmann B, Brenner H. Tobacco smoke exposure before, during, and after pregnancy and risk of overweight at age 6. Obesity (Silver Spring) 2011; 19: $2411-$ 2417.

9. Hill SY, Shen S, Locke Wellman J, Rickin E, Lowers L. Offspring from families at high risk for alcohol dependence: increased body mass index in association with prenatal exposure to cigarettes but not alcohol. Psychiatry Res 2005; 135: 203-216.

10. Leary SD, Smith GD, Rogers IS, Reilly JJ, Wells JC, Ness AR. Smoking during pregnancy and offspring fat and lean mass in childhood. Obesity (Silver Spring) 2006; 14: 2284-2293.

11. Huang RC, Burke V, Newnham JP, et al. Perinatal and childhood origins of cardiovascular disease. Int $J$ Obes (Lond) 2007; 31: 236-244.

12. Suzuki K, Ando D, Sato M, Tanaka T, Kondo N, Yamagata Z. The association between maternal smoking during pregnancy and childhood obesity persists to the age of 9-10 years. J Epidemiol 2009; 19: 136-142.

13. Durmus B, Kruithof CJ, Gillman MH, et al. Parental smoking during pregnancy, early growth, and risk of obesity in preschool children: the Generation R Study. Am J Clin Nutr 2011; 94: 164-171.

14. Chen A, Pennell ML, Klebanoff MA, Rogan WJ, Longnecker MP. Maternal smoking during pregnancy in relation to child overweight: follow-up to age 8 years. Int $J$ Epidemiol 2005; 35: 121-130.
15. Hesketh K, Carlin J, Wake M, Crawford D. Predictors of body mass index change in Australian primary school children. Int J Pedr Obes 2009; 4: 45-53.

16. Beyerlein A, Toschke AM, von Kries R. Risk factors for childhood overweight: shift of the mean body mass index and shift of the upper percentiles: results form a crosssectional study. Int J Obes 2010; 34: 642-648.

17. Sharma AJ, Cogswell ME, Li R. Dose-response associations between maternal smoking during pregnancy and subsequent childhood obesity: effect modification by maternal race/ethnicity in a low-income US cohort. $A m$ J Epidemiol 2008; 168: 995-1007.

18. Koshy G, Delpisheh A, Brabin BJ. Dose response association of pregnancy cigarette smoke exposure, childhood stature, overweight and obesity. Eur J Public Health 2011; 21: 286-291.

19. Daniels SR. The use of BMI in the clinical setting. Pediatrics 2009; 124(Suppl 1): S35-S41.

20. Rogers I. The influence of birthweight and intrauterine environment on adiposity and fat distribution in later life. Int J Obes Relat Metab Disord 2003; 27: 755-777.

21. Wideroe M, Vik T, Jacobsen G, Bakketeig LS. Does maternal smoking during pregnancy cause childhood overweight? Paediatr Perinat Epidemiol 2003; 17: 171-179.

22. Ay L, Hokken-Koelega AC, Mook-Kanamori DO, et al. Tracking and determinants of subcutaneous fat mass in early childhood: the Generation R Study. Int J Obes (Lond) 2008; 32: 1050-1059.

23. Oken E, Huh SY, Taveras EM, Rich-Edwards JW, Gillman MW. Associations of maternal prenatal smoking with child adiposity and blood pressure. Obes Res 2005; 13: 2021-2028.

24. Kummeling I, Thijs C, Penders J, et al. Etiology of atopy in infancy: the KOALA Birth Cohort Study. Pediatr Allergy Immunol 2005; 16: 679-684.

25. Fredriks AM, van Buuren S, Wit JM, VerlooveVanhorick SP. Body index measurements in 1996-7 compared with 1980. Arch Dis Child 2000; 82: 107-112.

26. Valero De Bernabe J, Soriano T, Albaladejo R, et al. Risk factors for low birth weight: a review. Eur J Obstet Gynecol Reprod Biol 2004; 116: 3-15.

27. Fenercioglu AK, Tamer I, Karatekin G, Nuhoglu A. Impaired postnatal growth of infants prenatally exposed to cigarette smoking. Tohoku J Exp Med 2009; 218: 221-228. 28. Syme C, Abrahamowicz M, Mahboubi A, et al. Prenatal exposure to maternal cigarette smoking and accumulation of intra-abdominal fat during adolescence. Obesity 2010; 82: 1021-1025.

29. Russell T, Crawford M, Woodby L. Measurements for active cigarette smoke exposure in prevalence and cessation studies: why simply asking pregnant women isn't enough. Nicotine Tob Res 2004; 6: (Suppl 2):S141-S151. 30. Patrick DL, Cheadle A, Thompson DC, Diehr P, Koepsell T, Kinne S. The validity of self-reported smoking: a review and meta-analysis. Am J Public Health 1994; 84: 1086-1093.

31. Scholtens S, Brunekreef B, Visscher TL, et al. Reported versus measured body weight and height of 
4-year-old children and the prevalence of overweight. Eur $J$ Public Health 2007; 17: 369-374.

32. Dubois L, Girad M. Accuracy of maternal reports of pre-schoolers' weights and heights as estimates of BMI values. Int J Epidemiol 2007; 36: 132-138.

33. Wells JC, Fewtrell MS. Measuring body composition. Arch Dis Child 2006; 91: 612-617.

34. Liem ET, De Lucia Rolfe E, L'Abée C, Sauer PJJ, Ong

$\mathrm{KK}$, Stolk RP. Measuring abdominal adiposity in 6 to 7-year-old children. Eur J Clin Nutr 2009; 63: 835841.

\section{Supporting information}

Additional Supporting Information may be found in the online version of this article:

Appendix S1. Baseline characteristics of participants in the present study.

Appendix S2. Agreement between overweight based on parent-reported data and data measured at home visits at age 6-7 years. 